\title{
ENTREVISTA COM JUAN CARLOS PINTO QUINTANILLA ${ }^{1}$
}

[RCJ] ${ }^{2}$ : Houve, na Bolívia, uma quebra de institucionalidade do Estado Democrático de Direito com a renúncia do presidente Evo Morales? Não é inconstitucional a tentativa de Evo de se repostular presidente de maneira indefinida? Não foi legal a posse na presidência por parte da senadora Jeanine Áñez?

[JCPQ]: Tais perguntas possuem duas dimensões inter-relacionadas, certamente. No entanto, começamos por não permanecer somente no âmbito da resposta jurídica, a qual, sem dúvidas, apresenta argumentos suficientes, baseados na legislação boliviana, para sustentar a possibilidade da reeleição de Evo Morales. Porém, considerando o contexto mundial, que, definitivamente, não permite uma receita política da democracia acerca do tema da alternância, pois, em cadapaís foram criadas, na legislação, exceções, por razões de exercício de um papel de liderança consolidado ou em ou emergência, bem como da necessidade de conservar a unidade do país;definitivamente, existem líderes mundiais do primeiro mundo que sustentam sua liderança no marco de suas próprias condições. Inclusive poderíamos denunciar a hipocrisia democrática quando a alternância mencionada é somente uma mudança de rostos, quando, na realidade, permanece o mesmo sistema e o mesmo modelo de governabilidade e não se vislumbram alternativas reais para a decisão cidadã. Portanto, o cenário das eleições também pode apresentar-se como cenário para assegurar o mesmo poder do capital e nos fazer crer que, na realidade, o elegemos. Frente a esta hipocrisia, na Bolívia, depois de 20 anos de revezamento de poder entre os neoliberais, quando os mesmos partidos realizavam alianças para repartirem o poder, é que ocorre a decisão da maioria da população de sustentar uma liderança fundamental e criar as condições para uma mudança de época no país. Não só foi uma votação histórica, mas três votações consecutivas tiveram uma participação de $80 \%$ a $90 \%$ do padrão eleitoral, dos quais Evo obteve os votos de $54 \%$ a $67 \%$, com o que pode obter

\footnotetext{
1 Sociólogo e analista político boliviano.

2 Entrevista realizada em espanhol por Daniel Araújo Valença: Doutor em Direito Universidade Federal da Paraíba (UFPB) e professor adjunto da Universidade Federal Rural do Semi-Árido (UFERSA). ORCID: https://orcid.org/0000-0002-0662-7045. Tradução para o português por Enzo Bello: Doutor em Direito pela UERJ. Estágio de Pós-Doutorado em Direito pela UNISINOS. Estágio de Pós-Doutorado em Serviço Social pela UFRJ. Professor Adjunto da Faculdade de Direito da UFF. Professor e ex-coordenador do Programa de PósGraduação em Direito Constitucional (PPGDC) da UFF. Editor-chefe da Revista Culturas Jurídicas (www.culturasjuridicas.uff.br). Membro do Núcleo de Estudos e Projetos Habitacionais e Urbanos (NEPHU) da UFF. Consultor da CAPES). ORCID: https://orcid.org/0000-0003-3923-195X.
} 
governabilidade nestes quase 14 anos. Então, não só nos referimos ao apoio popular, mas também às condições políticas nas quais a maioria criou essa liderança histórica. Não há dúvidas que existiram tarefas não cumpridas que passavam pela constituição de novas lideranças e por uma formação política que permitissem uma maior deliberação política neste cenário, o que gerou um nível de dependência da liderança; e não só isso: o Estado Plurinacional se converteu em um instrumento político e não o MAS-IPSP, que se tornou um mero instrumento eleitoral. Essa condição, precisamente, foi a que permitiu que não existisse um comando político que pudesse tomar decisões políticas que viessem a enfrentar as condições do golpe que se formava - dentre elas, justamente depender do alinhamento político da liderança e não de um conjunto de atores políticos que não cedessem, ante à ausência de presidente, a um artifício legal pelo qual a senhora Añez tomou a presidência, quando o MAS tem 2/3 do Parlamento e as duas presidências de câmaras, ou seja, a sucessão constitucional deveria recair em outro representante do MAS, e não na senhora Añez, cujo partido obteve menos de $4 \%$ da votação, e é com dito apoio que se assume no cargo de fato que exerce até hoje.

[RCJ]: Durante o governo Evo Morales, houve alguma mudança em relação ao tema das Forças Armadas e da Polícia?

[JCPQ]: Se houve aspectos que permitiram a inclusão na oficialidade de ambas as instituições, foi a previsão de cotas para os povos indígenas. Sem embargo, em essência, nunca se transformou a institucionalidade de hierarquias e de classe que existe no interior de ambas as instituições. No caso da Polícia, que é essencialmente corrupta em sua própria constituição, defenderam o tema de não serem tocadas e nunca permitiram que houvesse uma investigação e transformação institucional. Por sua parte, o Exército, que teve apoio do presidente, na realidade se adaptou às condições políticas, e se livrou do rosto golpista do passado fazendo trabalhos humanitários que lhe permitiu ter outro perfil diante da população. Em essência, nunca deixaram de ser corpos repressivos que, segundo a correlação de forças, estavam atentos à recuperação do poder dos setores tradicionais. Institucionalmente vivem as contradições de classe, pois enquanto a oficialidade é parte das elites oligárquicas e de classes médias tradicionais, a tropa em ambos os casos é fundamentalmente indígena originária e camponesa. 
[RCJ]: O Estado Plurinacional seria uma ilusão jurídica? O que explica a queda da ordem constitucional criada em 2009?

[JCPQ]: Demos passos importantes na inclusão real da diversidade, e hoje são direitos adquiridos; sem embargo, as tarefas maiores não puderam ser abordadas na perspectiva de que a diversidade se convertesse em conteúdo político diferenciado do Estado como concentração de poder. Faltou potencializar justamente o protagonismo político do sujeito histórico, que de alguma maneira foi substituído pelo próprio Estado. A Constituição Política do Estado (CPE) de transição de 2009, gerou condições de encontro entre as duas Bolívias, mas que agora está em perigo frente à nova arremetida dos setores oligárquicos.

[RCJ]: Como está a correlação de forças e qual o cenário que enxergas para o futuro?

[JCPQ]: As lutas sociais na Bolívia sempre tiveram, além de um conteúdo de classe, uma reivindicação da identidade frente à discriminação histórica e racial por parte daqueles que governaram o país. Por isso, esta reivindicação estrutural é a que permitiu que um "índio" fosse escolhido como presidente de todos os bolivianos, a partir da maioria. As minorias não haviam sido capazes de construir um país para todos, as maiorias votaram em um deles para construir um país diferente, e durante 13 anos foram construídas pontes de interculturalidade e inclusão que fizeram desta sociedade racializada um espaço de construção de Democracia Intercultural. Não só se assumiu a maioria como votante, mas como ator político, o Estado se permeabilizou à representação Indígena Originário Camponesa (IOC) e à equidade de gênero, que também foi outro dos fatores de exclusão das oligarquias. Se bem que não se expropriou nem excluiu as minorias, e inclusive muitos deles tiveram melhores condições econômicas e de representação democrática; se priorizou o acesso das maiorias a melhores condições de vida e a uma maior e proporcional representação política em todos os espaços estatais.

As confrontações de classe permeadas com o racismo expressado na confrontação, nunca foram um fator novo, sempre estiveram presentes no discurso e na ação das minorias, enquanto as maiorias optaram politicamente apenas pelo exercício de seus direitos na cidadania intercultural que se estava construindo. Por isso a irrupção das minorias, a tomada inicial das ruas, junto à cumplicidade da oficialidade tanto do Exército como da Polícia, mostram uma irrupção do poder de classe, que se rebelam frente ao poder popular, frente aos 
direitos de todos sem privilégios, tão ansiados por eles: é a vingança de classe por tantos anos de ter vivido a igualação social que vivemos.

Para eles, junto a seus meios de comunicação e às redes, significou a violação da "democracia", em realidade de seus privilégios; e ainda que se possa assumir erros cometidos no campo popular em sua estratégia de governo, sempre o fator de aproveitamento classista para somar descontentamento foi um fator fundamental, que ademais não pode dissimular nem nos maiores discursos dos golpistas, o fator racial como fator de poder. Englobaram o racismo no Masismo (referência aos militantes do MAS-IPSP, partido de Evo e Linera) e a todos eles se referem como "hordas" ou como delinquentes, pois assim pensam sobre a “indianidade" que expressa o país; pois, enquanto isso ocorre, não é estranho que os setores médios, da juventude "cruceñista" ou a juventude "Kochala" (organizações juvenis de extrema direita), que queimaram 5 tribunais eleitorais departamentais, e outros edifícios públicos, recebam o apelativo de "patriotas". Tampouco é estranho que enquanto eles violentavam as ruas, não haviam recebido nenhum ferido, e pelo contrário os setores populares mobilizados, tiveram mais de 34 mortos e mais de 1000 feridos, e o mesmo número de detidos, não é este também um fator racial e de classe? Não o é também que a oficialidade policial publicamente queime a Wiphala ou a cortem de seu uniforme, frente ao perdão pedido pelos policiais de base que são Aymaras?

Vivemos quase 14 anos de construção de uma Democracia Intercultural, e hoje a partir dos acontecimentos que derivaram na renúncia de Evo Morales, voltamos à condição de enfrentamento classista e racial dos setores dominantes, com maiores dores e mortos fruto da mobilização popular que se mobiliza convencida de que defende um processo que lhes pertence. Sem embargo, neste contexto, o órgão Legislativo que em sua grande maioria segue tendo o MAS IPSP como representação fundamental, buscou gerar novas pontes de encontro que permitam a pacificação do país, e que permita a instauração de novas eleições com um novo Órgão Eleitoral.

Então partimos da premissa de que se perdeu uma batalha, das ruas e do discurso; mas que as confrontações devem retomar um curso organizativo e institucional, que retomando de modo autocrítico o proceder político desta conjuntura, nos permita rearmar politicamente o Instrumento, que representa $50 \%$ da população votante, e que a partir de uma mirada autocrítica e da potencialização de novas lideranças, permita conjunturalmente participar na disputa eleitoral pela representação daqueles que como maioria ainda sustentam o único Instrumento político com representação nacional, frente a uma oposição atomizada que 
sustenta como proposta a negação do processo de mudança e o descontentamento, e que apenas buscará justificar seu projeto alternativo nas carências, assim como no racismo, antes que nas propostas de sustentabilidade tanto da economia como dos caminhos de encontro e interculturalidade que até agora não foram capazes de oferecer para a pacificação do país.

A retomar o caminho da democracia intercultural como alternativa fundamental frente ao racismo, a recuperar a representação de base como essência dessa Democracia, a mobilizarmos para defender nossos direitos fundamentais, a defender a representação de maioria que nos construiu como país de todas e todos, a continuar com a revolução para seguir construindo uma Pátria para todos. 